\title{
TRISTAN DA CUNHA 1962
}

\section{THE ROYAL SOCIETY'S EXPEDITION AND WILDLIFE PRESERVATION}

\author{
By H. F. I. ElliotT
}

The evacuation of Tristan da Cunha following the volcanic eruption of 9th October, 1961, has again raised the question ${ }^{\star}$ of safeguarding one of the richest reservoirs of oceanic wildlife left in the world.

Since measures for wildlife protection were initiated in 1950-2, there have been no reports of further deterioration of the fauna and flora, and indeed the position of some species, such as the winter-breeding mutton bird or long-winged petrel and the seals, is said to have improved considerably, particularly on the main island where impoverishment had been most marked. The regulations governing the exploitation of wildlife were fairly well observed; pests, predators, and damage to habitat by domestic animals and fuel-cutting were held in check.

In contrast to the majority of small islands at low latitudes, the wildlife of the Tristan group has thus been relatively unimpaired. Of outstanding ornithological interest, the group remains the only breeding-station of the great shearwater Puffinus gravis, and of several distinct races of seabirds, while the ten different forms of thrushes, buntings, and rails rank with the finches of the Galapagos in importance for the study of evolution. Special mention might be made of the Inaccessible Island flightless rail, Atlantisia, discovered as recently as 1924, and surely one of the most attractive as well as rarest little creatures to be found anywhere.

Apart from birds, the islands of the group support an expanding population of elephant seals, fur seals, and right whales, the last two of species at one time thought to be nearing extinction. Botanically the small number of species is offset by their outstanding interest, particularly that of some of the mosses and ferns, while the field of study for the entomologist and marine biologist is extensive and still far from being fully explored.

It was clear that the sudden evacuation of the 150-year-old settlement, leaving the islands uninhabited except for the South African meteorological station on Gough, might well constitute a threat to the wildlife, despite the immediate relief to species exploited for human consumption, which latterly has been largely restricted to the sooty and yellow-nosed albatross, the great shearwater, mutton bird, and rockhopper penguin. The threat falls under two heads :-

(a) First and most immediate is the possible effect of uncontrolled pests and abandoned livestock. Of the pests rats and feral cats are the most likely to be harmful. Rats have spread all over the main island, but

* See also Oryx, III, 1, March, 1953, "The Fauna of Tristan da Cunha," by H. F. I. Elliott. 
tend to be attracted to the settlement and potato-patches, where about a thousand were destroyed annually. The end of this check may result in an initial increase and spread, and it is doubtful whether the addition of surviving domestic cats to the remnant of the feral stock will improve matters. As soon as the supply of fowls and village refuse is exhausted, the likely victims are birds, young seals, and even the vegetation, since the rats are partly herbivorous.

In addition to cats and a few dogs which have escaped destruction, abandoned domestic animals include cattle, sheep, donkeys, geese, and fowls, the last three confined to the settlement area. Experience has shown that, besides human consumption, climate and terrain take a substantial toll, while many pastures liable to final ruination if there is much further increase of stock, are at least circumscribed by impassable cliffs and ravines. Nevertheless it seems likely that, unless some control measures can be devised, growing damage to the habitat and so to the wildlife is inevitable. This applies particularly to damage by the sheep, at present not more than a hundred, which roam freely over the upper slopes of the mountain.

(b) The second, rather more indirect, threat to the wildlife stems from the disappearance of local administrative control and the valuable day-today information which the islanders, knowing and frequently penetrating to every corner of their island home, were able to supply. It is true that a number of species should thrive from lack of exploitation, and it will be particularly interesting to see whether in the case of an aggressive species, such as the great shearwater, an "explosion" occurs akin to that of the fulmar in northern latitudes. It is also true that experience with the weather station on Gough, gives confidence that the co-operation of the authorities and personnel likely to be concerned with future visits to Tristan, can be counted upon. Nevertheless there are many instances in the world of the disastrous effects on flora and fauna of occasional thoughtlessness and ignorance. To keep a watchful eye on conservation was one of the responsibilities of the island's administrator and, without him, the risks are certainly greater, especially for such valuable and vulnerable species as the fur seal and for rarities like Wilkins's bunting, of which probably less than a hundred exist and specimens of which unfortunately command a high price.

It was with these considerations in mind that the Trustees of the World Wildlife Fund, in consultation with the International Union for the Conservation of Nature, decided to offer a contribution to enable a "biological wing" to be added to the Royal Society's expedition to Tristan da Cunha. This expedition had been planned by geologists with the primary purpose of investigating the nature and progress of the eruption which had so unexpectedly disturbed the long quiescence of the southern end of the mid-Atlantic ridge. It was hoped, also, by a detailed survey of the geology to establish the succession of events in Tristan's volcanic history and perhaps to elucidate the causes and probable course of the present eruption. In this task biological investigation of quaternary deposits will be especially relevant, besides adding to knowledge of past changes in the flora and fauna. 
The World Wildlife Fund's prompt response to an emergency situation meant that three members of the expedition, a botanist, a zoologist, and the Island's own agriculturist, who has spent the last four years on Tristan, will be able to devote special attention to the present and future needs of conservation. The expedition sailed from Cape Town on 22nd January, and is expected to spend eight to ten weeks on the island, all too short a time for the wide field demanding investigation, but enough, it is hoped, to make a most valuable and timely contribution to the immediate objectives. These, in conclusion, may be very briefly summarized as :-

(a) Assessing the direct and indirect effects of the eruption on the fauna and flora ;

(b) taking any immediate steps found practicable and desirable to safeguard the habitat, natural resources, and wildlife;

(c) bringing up to date and extending knowledge of the ecology and of the status of all species of special interest; and

(d) making recommendations for long-term conservation and for such further biological studies as may be necessary to provide a sound basis for conservation. 